\title{
Alcohol consumption in Russia: Distorted vision
}

\section{Jargin $\mathrm{SV}^{*}$ \\ Peoples' Friendship University of Russia, Russia}

The problem of excessive alcohol consumption in Russia is well known; however, there is a tendency to exaggerate it, which seems to be used to disguise shortages of the healthcare and the fact of legal trade with falsified beverages and surrogates [1]. In this way, responsibility for the relatively low life expectancy [2] is shifted upon patients, that is, supposedly self-inflicted diseases due to excessive alcohol consumption. In parallel, there seems to be a tendency to exaggerate efficiency of governmental policies.

To start with, the graph titled "Indices of real price, tax, affordability and per capita vodka sales, real disposable income, total alcohol consumption, total alcohol sales and unrecorded alcohol consumption in Russia (2010-1015)" [3] does not start from zero, thus creating impression that affordability of vodka changed considerably. A similar graph was published in [4]. In fact, the average salary (pension) / minimal vodka price ratio oscillated and did not change significantly over the period 2010-1015 (Table 1), remaining several times higher than it had been prior to the anti-alcohol campaign (hereinafter campaign) started in 1985 [5].

Notes: Early in 2015 one US dollar was equivalent to approximately 60 roubles.

Here follow several citations with comments. "The real price of vodka has increased 2.4 times (from 230 to 559 roubles per 0.5 litre) during this period" i.e. 2010-2015 [4]. The term "real price of vodka" is used inadequately as vodka at minimal price (Table 1) has been broadly available in shops and supermarkets (Figure 1). In fact, the "real price" is the minimal price considering inflation; it is reflected by the ratio average salary (pension) / minimal price (Table 1).

"A significant decreasing in the affordability of vodka appears to have been a major driver of dramatic decreasing in vodka sales between 2010 and 2015" [4]. As discussed above, there was no "significant decreasing in the affordability of vodka" between 2010 and 2015 . Alcoholic beverages are several times more affordable than they had been prior to the campaign. Nonetheless, the alcohol consumption and heavy binge drinking in Russia tend to decrease since the last decade at least [6]. In the author's opinion, among the principal causes of the decrease in alcohol consumption are the responsible way of life under conditions of the market economy, intimidation and harassment of alcoholics, crime against them aimed e.g. at appropriation of their flats and houses [7]. All that do not predispose to leisure drinking.

Table 1. Average monthly salaries, pensions and minimal vodka prices in Russian Federation (roubles).

\begin{tabular}{|c|c|c|c|c|c|}
\hline Year & $\begin{array}{c}\text { Average } \\
\text { salary* }\end{array}$ & $\begin{array}{c}\text { Average } \\
\text { pension* }\end{array}$ & $\begin{array}{c}\text { Min. vodka } \\
\text { price 0.5 l }\end{array}$ & $\begin{array}{c}\text { Salary/ } \\
\text { vodka price }\end{array}$ & $\begin{array}{c}\text { Pension/ } \\
\text { vodka } \\
\text { price }\end{array}$ \\
\hline 2010 & 21,000 & 7,500 & 90 & 233 & 83 \\
\hline 2014 & 32,500 & 10,800 & 220 & 148 & 49 \\
\hline 2015 & 33,100 & 10,900 & 185 & 178 & 59 \\
\hline
\end{tabular}

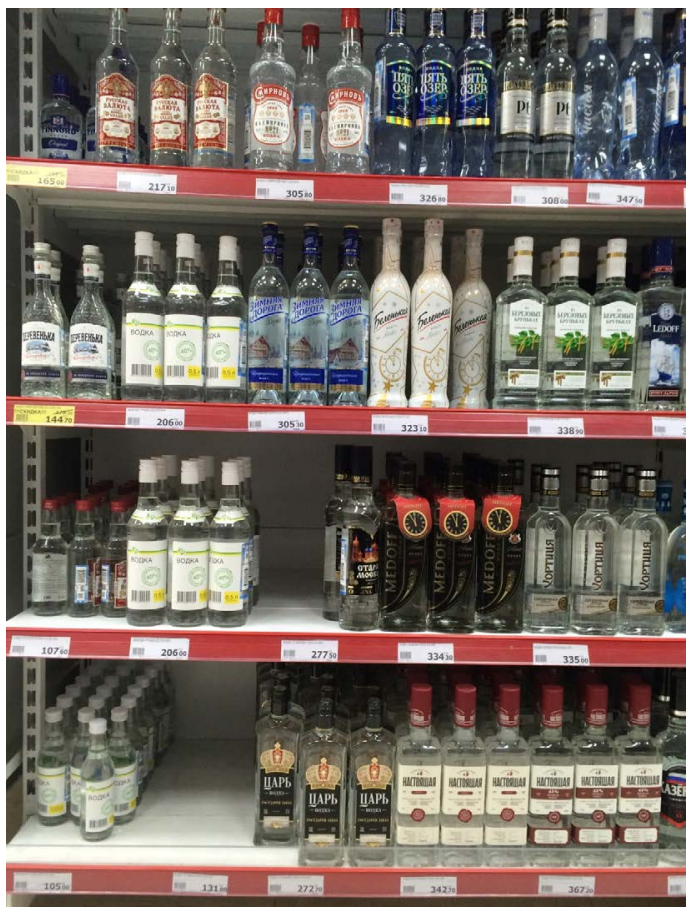

Figure 1. Vodka in a supermarket near the centre of Moscow (February 2018); minimal price for a 0.51 bottle -206 roubles.

As for younger people, they seem to overtake the moderate alcohol consumption style prevailing in other countries.

"In 2016, almost 80 people died as a result of mass methanol poisoning in Irkutsk, one of the largest cities in Siberia. The fatalities in this city occurred after people turned into a bath lotion "Bouaryshnik" (howthorn) as a cheap substitute for vodka. The product normally contains 93\% ethanol, hawthorn extract and lemon oil...." [4]. In our opinion, the poisonings could have been caused by hawthorn (Crataegus) tincture sold in pharmacies and containing $70 \%$ ethanol [8]. The hawthorn tincture is known as the pharmacy product most frequently used by drinkers in Russia $[9,10]$. Some consumers purchase pharmacy tinctures not because of the low price but as they hope to obtain better quality alcohol than vodka from the shop. No information on hawthorn bath lotion containing $93 \%$ of ethanol has been found. There could have been misinformation intended to disguise the fact that methanol was used as a substitute for medicinal ethanol.

Correspondence to: Jargin SV, Peoples' Friendship University of Russia, Moscow Clementovski per 6-82; 115184 Moscow, Russia, E-mail: sjargin@mail.ru

Received: February 19, 2018; Accepted: March 09, 2018; Published: March 13 2018 
The statement "one of the consequences of the legal alcohol shortages in 2006 was the appearance of alcohol surrogates including household chemistry liquids with new denaturant additives" [3] creates impression that consumers deliberately purchase technical liquids for drinking. In fact, the surrogates in vodka bottles, labelled as ordinary vodka, were sold through legally operating shops and kiosks [11,12], being indistinguishable by sight from authentic products. It is known by inside observers that consumption of technical liquids, lotions etc. decreased abruptly after the campaign - thanks to the "sudden availability of cheap alcohol" [13]. The concept that alcoholics would voluntarily drink surrogates when regular beverages are available is unfounded. They have their experience, distinguish between high and low-quality products, know their ailments that may exacerbate after the intake of poor-quality alcohol. Some alcoholics would never drink beer if it smells technical alcohol. However, ethanol from non-edible sources (synthetic and cellulosic) has been used after the campaign for production of legally sold beverages. Official permissions to use such alcohol were issued during the 1990s [14,15]. Permissions were later revoked; however, in conditions of disregard for some laws and regulations, the use of technical alcohol has been continued. Admittedly, the following statement can be agreed with: “...objection to pricing policy as a public health strategy is that heavy drinkers are likely to switch to alcohol surrogates as a substitute for legal alcohol, which it cannot afford to buy" [3]. So it happened during the campaign, when availability of alcoholic beverages was limited indeed, while consumption of technical liquids and lotions increased considerably [14]. Many distilleries producing vodka from grain and potatoes were dismantled at that time. After the campaign, technical alcohol found no demand from the stagnating industry. It was generally known and smelled by the drinking public that technical liquids were used for production of beverages legally sold in bottles with usual labels. The astringent taste of technical alcohol was known by the drinking public as it was purloined from some factories, scientific institutions etc. Reportedly, about a half of lethal poisonings by alcohol-containing liquids in the 1990s was caused in some areas by legally sold beverages [16]. There seems to be an improvement tendency; however, even today, according to Deputy Prime Minister of Russian Federation Alexander Khloponin, about $40 \%$ of Cognac legally sold in Russia is falsified (Figure 2). Real figures may be higher.

After the failure of the campaign in 1989, alcoholic beverages have become easily available; queues have disappeared. The state alcohol monopoly was revoked in 1992. As mentioned above, synthetic and cellulosic alcohol gained access to the beverage market: mixed with water, it was sold as vodka, added to beer, wine and other beverages $[14,16,17]$. Synthetic alcohol was imported to Russia from neighbouring countries: queues of tankers with ethanol were observed at border crossings. Whether and how these gasoline tankers were cleaned, is unknown. The disdainful attitude of some new Russian business to the mass consumer is known. North Caucasus has been generally known as a nationwide source of cheap alcoholic beverages [14]. Technical alcohol was diluted and poured out into vodka bottles. It can be reasonably assumed that for small manufacturers it is uneconomic to properly wash the bottles and to purchase necessary equipment. Cases of e.g. organochloride poisoning from the contents of vodka bottles are known [6].

Illegal trade with alcoholic beverages e.g. on the Internet does reportedly exist (our attempts to find it online have been unsuccessful) but "typically for bulk orders only" [18], while the falsified products are sold to consumers through legal shops, supermarkets and eateries. Apart from rather limited sales of homemade alcohol (samogon) mainly to ено | https://news.mail.ru/economics/32578349/?frommail=1

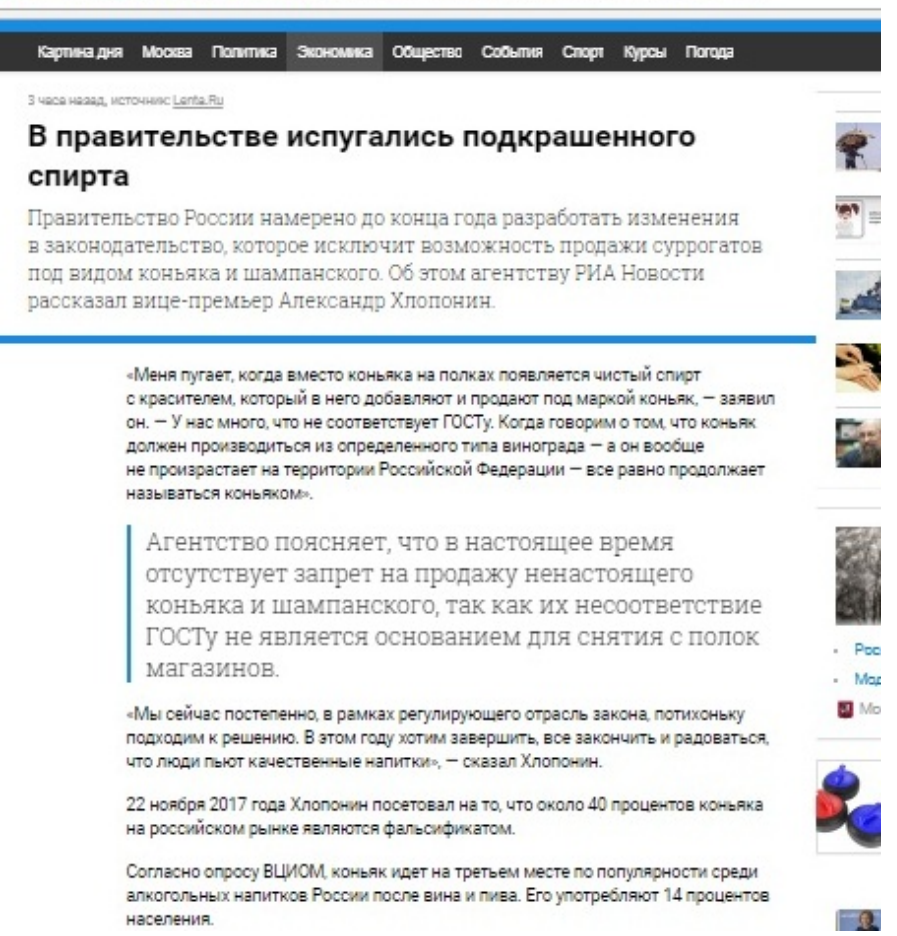

Figure 2. https://news.mail.ru (16 February 2018), partial translation: it is currently not prohibited to sell falsified Cognac and Champagne. On 22 November 2017 Khloponin complained that about $40 \%$ of Cognac on the Russian market is falsified.

neighbours in rural areas, a consumer usually has no possibility to go to the "black market" to purchase counterfeit alcohol at a low price. This seems to be not clearly understood by some foreign experts, which can be exemplified by the following citation: “... when faced with a branded vodka at the minimum price and a counterfeit vodka, the consumer will always choose the branded vodka" [19]. In fact, consumers are usually unable to distinguish by sight between branded and counterfeit vodka as it is sold at the same shops and looks identical or almost identical. In the 1990s, slanting labels and lax closures were known as attributes of falsified beverages. Today, falsified and authentic products are hardly distinguishable by sight: the bottles are "in good accordance with the original products" [18].

"Finally, the unrecorded consumption of alcohol was commonplace in Russia throughout the study period, especially in the most recent years, when a considerable proportion of vodka came from illicit sources [4]. According to the World Health Organization [20], "unrecorded alcohol... is produced, distributed and sold outside formal channels." Falsified alcohol is sold in Russia through the formal channels (legally functioning shops and eateries) so it does not correspond to the WHO definition of unrecorded alcohol. If a bottle goes through the counter in a legal shop, it is recorded as sold alcohol. Moreover, the term "nondeceptive counterfeits (products of which the consumers are fully aware that they are counterfeits usually because of their cheap price)" [18] is inadequate in this context as the counterfeits may be "nondeceptive" for resellers but not a priori for consumers - before they smell and taste the product. Note that original and falsified products are often sold at the same shop or supermarket, being indistinguishable from each other by sight.

The last citation to be commented: "There are some indications, that mortality has been improving in Russia in the past decade, due 
in part to the government's measures that have made alcohol less affordable" [4]. The mortality is decreasing indeed, although statistics might be overstated to highlight successes of governmental policies [2]. In conclusion, certain publications on alcohol consumption in Russia are biased towards overestimation of successes of governmental policies and obfuscation of the problem of legally sold falsified beverages and surrogates; more details are in [21].

\section{References}

1. Jargin SV (2017) Popular alcoholic beverages in Russia with special reference to quality and toxicity. $J$ Addiction Prevention 5: 6.

2. Jargin SV (2015) Cardiovascular mortality trends in Russia: possible mechanisms. Nat Rev Cardiol 12: 740. [Crossref]

3. Razvodovsky YE (2017) The effects of alcohol taxation and pricing policies on unrecorded alcohol consumption in Russia. J Alcohol Drug Depend 5: 294.

4. Razvodovsky YE (2017) The effects of alcohol taxation and pricing policies on vodka sales in Russia. $J$ Addict Ther Res 1: 22-25.

5. Jargin SV (2017) Alcohol and alcoholism in Russia: Policies and their effects. Archives Medical Review Journal 26: 207-222.

6. Jargin SV (2016) Alcohol Abuse and Toxicity of Alcoholic Beverages in Russia: Recent history. ARC J Addiction 1: 21-29.

7. Jargin SV (2010) Social vulnerability of alcoholics and patients with alcohol-related dementia: a view from Russia. Alcohol Alcohol 45: 293-294.

8. Jargin SV (2016) Questionable information on poisonings by alcohol surrogates. Interdiscip Toxicol 9: 83-84. [Crossref]

9. Gil A, Polikina O, Koroleva N, McKee M, Tomkins S, et al. (2009) Availability and characteristics of nonbeverage alcohols sold in 17 Russian cities in 2007. Alcohol Clin Exp Res 33: 79-85. [Crossref]
10. Monakhova YB, Kuballa T, Leitz J, Lachenmeier DW (2011) Determination of diethyl phthalate and polyhexamethylene guanidine in surrogate alcohol from Russia. Int $J$ Anal Chem 2011: 704795. [Crossref]

11. Luzhnikov EA (2014) Medical toxicology. Moscow: Geotar-Media.

12. Ostapenko YN, Brusin KM, Zobnin YV, Shchupak AY, Vishnevetskiy MK, et al. Acute cholestatic liver injury caused by polyhexamethyleneguanidine hydrochloride admixed to ethyl alcohol. Clin Toxicol 49: 471-477. [Crossref]

13. Keenan K, Saburova L, Bobrova N, Elbourne D, Ashwin S, et al. (2015) Social factors influencing Russian male alcohol use over the life course: A qualitative study investigating age based social norms, masculinity, and workplace context. PLoS One 10: e0142993. [Crossref]

14. Nemtsov AV (2009) Alcoholic history of Russia: contemporary period. Moscow: urss.ru.

15. Savchuk SA, Nuzhnyi VP, Rozhanets VV (2016) Chemistry and toxicology of ethyl alcohol and beverages on its basis: chromatographic analysis of alcoholic beverages. Moscow: urss.ru.

16. Nuzhnyi VP, Kharchenko VI, Akopian AS (1998) Alcohol abuse in Russia is an essential risk factor of cardiovascular diseases development and high population mortality (review). Ter Arkh 70: 57-64. [Crossref]

17. Nuzhnyi VP (1995) Toxicological characteristic of ethyl alcohol, alcoholic beverages and of admixtures to them. Voprosy Narkologii 3: 65-74.

18. Neufeld M, Lachenmeier DW, Walch SG, Rehm J (2017) The internet trade of counterfeit spirits in Russia - an emerging problem undermining alcohol, public health and youth protection policies? 6: 520 .

19. Bailey A (2014) Campaign, simulation, or what? President Medvedev's anti-alcoho initiative, 2009-2012. In: Materials of the Fifth International Scientific-and-Practical Conference "Alcohol in Russia", 10: 119-124.

20. World Health Organization (2011) Global status report on alcohol and health, Geneva.

21. Jargin SV (2018) Alcohol-related poisonings in Russia: Obfuscated facts. J Addict Ther Res 2: 1-5.

Copyright: (C2018 Jargin SV. This is an open-access article distributed under the terms of the Creative Commons Attribution License, which permits unrestricted use, distribution, and reproduction in any medium, provided the original author and source are credited. 